\title{
Contribution of the scrotum and testes to scrotal and testicular thermoregulation in bulls and rams
}

\author{
J. P. Kastelic, R. B. Cook and G. H. Coulter \\ Research Centre, Agriculture and Agri-Food Canada, PO Box 3000, Lethbridge, Alberta, \\ Canada T1J $4 B 1$
}

\begin{abstract}
A novel model was used to determine the role of the scrotum and testes in scrotal/testicular thermoregulation in bulls and rams. Eleven yearling bulls and 12 yearling rams were used at an ambient temperature of $15^{\circ} \mathrm{C}$. The distal lateral aspects and entire ventral part of the scrotum were incised under caudal epidural analgesia (xylazine, $0.07 \mathrm{mg} \mathrm{ml}^{-1}$ ). Both testes were withdrawn from the scrotum, the vaginal tunic was removed and one testis was replaced in the scrotum. Surface and internal temperatures were measured with infrared thermography and needle thermocouples, respectively. Temperature gradients (difference in temperature from top to bottom; ${ }^{\circ} \mathrm{C}$ ) for bulls and rams, respectively, were: scrotal surface (with replaced testis) 2.1 and 3.5; scrotal surface (without testis) 2.5 and 3.6; scrotal subcutaneous (with replaced testis) 1.0 and 0.7; testicular subtunic (without scrotum) -0.7 and -0.3 ; deep intratesticular (with scrotum) -0.2 and -0.6 ; and deep intratesticular (without scrotum) -0.5 and -0.5 . Results supported the hypotheses that the scrotum has a positive temperature gradient (warmer at the top than the bottom) and that the testis has a negative temperature gradient (warmer at the bottom than the top). These opposing gradients apparently complement one another, resulting in a relatively uniform intratesticular temperature, below body core temperature, that is essential for normal sperm production. The scrotum substantially increased intratesticular temperature, but scrotal surface temperature was not significantly affected by the presence of a testis.
\end{abstract}

\section{Introduction}

Maintenance of a uniform intratesticular temperature between $2^{\circ} \mathrm{C}$ and $6^{\circ} \mathrm{C}$ lower than body-core temperature is essential for normal spermatogenesis in bulls (Waites, 1970). Several factors contribute to scrotal and testicular thermoregulation (Coulter and Kastelic, 1994) including the structure of the scrotum which holds the testes away from the body (Carrick and Setchell, 1977) and the testicular vascular cone which reduces testicular temperature by both countercurrent heat exchange (Gunn and Gould, 1975; Cook et al., 1994) and radiation from the scrotal surface (Coulter, 1988). In addition, the tunica dartos muscle affects the location of the testes relative to the body (Setchell, 1978) and scrotal sweat glands provide evaporative cooling (Blazquez et al., 1988).

In an earlier study (Riemerschmid and Quinlan, 1941), scrotal surface temperature in a bull decreased from the top of the scrotum to the bottom, but intratesticular temperature was relatively uniform. Similar findings were reported in rams (Fowler, 1968); scrotal subcutaneous temperature decreased from the top of the scrotum to the bottom and intratesticular temperature was relatively uniform. In a recent study (Kastelic et al., 1995), scrotal surface temperature of bulls had a positive top-to-bottom temperature gradient (average, $1.6^{\circ} \mathrm{C}$ ), with the

Received 5 January 1996. top of the scrotum warmer than the bottom. There was also a positive temperature gradient in the scrotal subcutaneous tissues $\left(0.4^{\circ} \mathrm{C}\right)$ and a slightly negative gradient within the testicular parenchyma $\left(-0.1^{\circ} \mathrm{C}\right)$. Therefore, while the scrotal surface temperature had a substantial positive temperature gradient, the testicular parenchyma was relatively uniform. Kastelic et al. (1995) suggested that these gradients may be due to the arrangement of the vasculature. The scrotum is apparently vascularized from the top to the bottom. Conversely, the testicular artery courses the length of the testis to the ventral pole and then diverges into several smaller arteries which spread dorsally and laterally across the surface of the testis before entering the testicular parenchyma (Setchell, 1970). If heat is lost from the testicular artery between the bottom of the testis and the point of entry into the parenchyma, then the testis may be warmer at the bottom than at the top (there is a negative testicular temperature gradient). If so, perhaps an opposing temperature gradient within the scrotum complements that within the testis, resulting in the relatively uniform intratesticular temperatures previously described (Riemerschmid and Quinlan, 1941; Fowler, 1968; Kastelic et al., 1995).

The objective of this study was to determine the role of the scrotum and testes in scrotal and testicular thermoregulation in bulls and rams. The following hypotheses were tested: (1) the scrotum has a positive temperature gradient (is warmer at the 
Table 1. Mean ( \pm SEM) surface temperatures $\left({ }^{\circ} \mathrm{C}\right.$ ) of the scrotum (with or without a testis) in bulls and rams

\begin{tabular}{|c|c|c|c|c|c|c|}
\hline \multirow[b]{2}{*}{ Location } & \multicolumn{2}{|c|}{$\begin{array}{l}\text { Scrotum } \\
\text { with testis }\end{array}$} & \multicolumn{2}{|c|}{$\begin{array}{c}\text { Scrotum } \\
\text { without testis }\end{array}$} & \multicolumn{2}{|c|}{$\begin{array}{c}\text { Effect of testis } \\
\text { on scrotal surface } \\
\text { temperature }\end{array}$} \\
\hline & Bull & Ram & Bull & Ram & Bull & Ram \\
\hline Top & $30.0 \pm 0.6^{\mathrm{a}}$ & $30.4 \pm 0.9^{\mathrm{a}}$ & $29.9 \pm 0.6^{a}$ & $30.7 \pm 0.7^{a}$ & 0.1 & -0.3 \\
\hline Middle & $29.0 \pm 0.6^{b}$ & $30.0 \pm 0.7^{\mathrm{b}}$ & $28.8 \pm 0.7^{b}$ & $30.5 \pm 0.8^{a}$ & 0.2 & -0.5 \\
\hline Bottom & $27.9 \pm 0.6^{c}$ & $26.9 \pm 1.0^{b}$ & $27.4 \pm 0.7^{\mathrm{c}}$ & $27.1 \pm 0.9^{b}$ & 0.5 & -0.2 \\
\hline Gradient & 2.1 & 3.5 & 2.5 & 3.6 & -0.4 & -0.1 \\
\hline
\end{tabular}

Within columns, means with different superscripts are significantly different $(P<0.01)$.

top than at the bottom), and (2) the testes have a negative temperature gradient (are warmer at the bottom than at the top).

\section{Materials and Methods}

Two experiments were conducted. In Expt I, II one-year-old Holstein bulls were examined in a controlled environment chamber at an ambient temperature of $15^{\circ} \mathrm{C}$. Scrotal surface temperature was measured by infrared thermography, with the camera (Thermovision 782; AGA Infrared Systems $A B$, Danderyd, Sweden) placed approximately $1 \mathrm{~m}$ behind the bull. Images were saved in a digital format and analysed using dedicated computer software (VIEWSOFT Version 1.2, Viewscan Ltd, Concord, ON). The scrotal surface temperature of the entire scrotum and the mean scrotal surface temperature for a line the width of the scrotum and one pixel high was determined for locations corresponding to the top, middle and bottom of the underlying testes. Assessment of scrotal surface temperature was done before and approximately $20 \mathrm{~min}$ after administration of caudal epidural analgesia (xylazine $\mathrm{HCl}$, $0.07 \mathrm{mg} \mathrm{kg}^{-1}$; Rompun, Chemagro Ltd., Etobicoke, ON) as described by Kastelic et al. (1995). Immediately after measurement of scrotal surface temperature, the testes were pushed dorsally and the scrotum was incised along the lateral aspect (from the midpoint distally) of both testes and across the bottom of the scrotum. A sharp instrument was used and there was minimal haemorrhage. Both testes were withdrawn from the scrotum (the vascular cones were left intact). For each testis, the vaginal tunic was incised, the testis passed through the opening, the ligament of the tail of the epididymis broken (by traction) and the tunic allowed to retract dorsally. One testis was replaced and retained by clamping the edges of the scrotum with towel clamps. The exposed testis was grasped (with finger tips) from the anterior aspect and held away from the scrotum. Surface temperatures of the scrotum with testis, scrotum without testis and exposed testis were measured with infrared thermography (as described above) within $3 \mathrm{~min}$ after the scrotum was incised. Temperatures were determined on the posterior aspects of the top, middle and bottom of the exposed testis and at corresponding locations on the scrotum. Internal temperatures were measured at these same locations with needle thermocouples (18 gauge, 1.5 inch injection needles with copper and copper-constantan wires) as described by Kastelic et al. (1995). Each measurement took approximately $30 \mathrm{~s}$ to complete. To measure scrotal subcutaneous temperature, the thermocouple was inserted through the scrotal skin. For testicular subtunic temperature, the tip of the thermocouple was placed just under the tunica albuginea. Intratesticular temperature was measured by inserting the thermocouple approximately $3 \mathrm{~cm}$ into the testicular parenchyma, with the tip approximately in the region of the mediastinum testis. Intraepididymal temperatures were measured by inserting thermocouples into the caput, corpus and cauda epididymides of both testes (percutaneously for the covered testis and directly for the exposed testis). The interval from incision of the scrotum to completion of all temperature measurements did not exceed $20 \mathrm{~min}$. Bulls were castrated at the end of the experiment.

Student's paired $t$ test was used to compare scrotal surface temperature measurements before epidural analgesia and just before surgery. The same analysis was used to determine the effects of presence of a testis on scrotal surface and scrotal subcutaneous temperatures, the effects of presence of the scrotum on intratesticular and intraepididymal temperatures, and to compare testicular surface and subtunic temperatures. Multivariate analysis of variance with Hotelling's $t$ test (Johnson and Wichern, 1982; SAS, 1989) was used to determine differences between top and middle, top and bottom, and middle and bottom for scrotal surface, scrotal subcutaneous, intratesticular, and intraepididymal temperatures for each side.

In Expt 2, 12 yearling Romanov rams were maintained at an ambient temperature of $15^{\circ} \mathrm{C}$. Procedures and measurements were the same as in Expt 1 (including the epidural analgesia), except that intraepididymal temperatures were not determined.

\section{Results}

In Expt 1 (bulls), scrotal surface temperature was not affected $(P>0.05)$ by the epidural analgesia. Scrotal surface temperatures (means \pm SEM) before the epidural compared with just before surgery were $31.1 \pm 0.5$ and $30.5 \pm 0.6$ (top), $30.1 \pm 0.5$ and $29.4 \pm 0.7$ (middle) and $28.3 \pm 0.5$ and $28.4 \pm 0.7^{\circ} \mathrm{C}$ (bottom). All other measurements reported were obtained after surgery.

Top scrotal surface temperature was greater than the middle, which was greater than the bottom $(P<0.01$; Table 1$)$. There 
Table 2. Mean ( \pm SEM) subcutaneous temperatures $\left({ }^{\circ} \mathrm{C}\right.$ ) of the scrotum (with or without a testis) in bulls and rams

\begin{tabular}{|c|c|c|c|c|c|c|}
\hline \multirow[b]{2}{*}{ Location } & \multicolumn{2}{|c|}{$\begin{array}{l}\text { Scrotum } \\
\text { with testis }\end{array}$} & \multicolumn{2}{|c|}{$\begin{array}{c}\text { Scrotum } \\
\text { without testis }\end{array}$} & \multicolumn{2}{|c|}{$\begin{array}{l}\text { Effect of testis } \\
\text { on subcutaneous } \\
\text { temperature }\end{array}$} \\
\hline & Bull & Ram & Bull & Ram & Bull & Ram \\
\hline Top & $33.2 \pm 0.4^{\mathrm{a}}$ & $33.2 \pm 0.2^{\mathrm{d}}$ & $33.6 \pm 0.4^{\mathrm{a}}$ & $34.0 \pm 0.4^{\mathrm{f}}$ & -0.4 & $-0.8^{*}$ \\
\hline Middle & $33.1 \pm 0.3^{\mathrm{a}}$ & $32.7 \pm 0.3^{\mathrm{e}}$ & $33.0 \pm 0.3^{b}$ & $32.8 \pm 0.3^{8}$ & 0.1 & -0.1 \\
\hline Bottom & $32.2 \pm 0.3^{b}$ & $32.5 \pm 0.3^{e}$ & $31.5 \pm 0.5^{c}$ & $31.7 \pm 0.4^{\mathrm{h}}$ & 0.7 & $0.8^{*}$ \\
\hline Gradient & 1.0 & 0.7 & 2.1 & 2.3 & -1.1 & $-1.6^{*}$ \\
\hline
\end{tabular}

Within columns, means with different superscripts are significantly different $\left({ }^{\mathrm{abc}} P<0.01,{ }^{\mathrm{dc}} P<0.05,{ }^{\mathrm{fgh}} P<0.001\right)$.

*Temperature difference is significant $(P<0.01)$.

Table 3. Mean ( \pm SEM) intratesticular temperatures $\left({ }^{\circ} \mathrm{C}\right)$ of the covered or exposed testis in bulls and rams

\begin{tabular}{|c|c|c|c|c|c|c|}
\hline \multirow[b]{2}{*}{ Location } & \multicolumn{2}{|c|}{ Covered } & \multicolumn{2}{|c|}{ Exposed } & \multicolumn{2}{|c|}{$\begin{array}{l}\text { Effect of scrotum } \\
\text { on intratesticular } \\
\text { temperature }\end{array}$} \\
\hline & Bull & Ram & Bull & Ram & Bull & Ram \\
\hline Top & $33.5 \pm 0.3$ & $33.4 \pm 0.3^{\mathrm{a}}$ & $30.7 \pm 0.5^{d}$ & $30.8 \pm 0.4^{a}$ & $2.8^{* *}$ & $2.6^{* * *}$ \\
\hline Middle & $33.7 \pm 0.3$ & $33.7 \pm 0.2^{b}$ & $31.2 \pm 0.5^{\mathrm{e}}$ & $31.1 \pm 0.4^{b}$ & $2.5^{*}$ & $2.6^{* * *}$ \\
\hline Bottom & $33.7 \pm 0.3$ & $34.0 \pm 0.2^{c}$ & $31.2 \pm 0.4^{\mathrm{e}}$ & $31.3 \pm 0.4^{c}$ & $2.5 * *$ & $2.7 * *$ \\
\hline Gradient & -0.2 & -0.6 & -0.5 & -0.5 & 0.3 & -0.1 \\
\hline
\end{tabular}

Within columns, means with different superscripts are significantly different $\left({ }^{\mathrm{abc}} P<0.01,{ }^{\mathrm{de}} P<0.05\right)$. Superscripts for temperature difference indicate significance $(* P<0.001, * * P<0.0001)$.

Table 4. Mean ( \pm SEM) surface and subtunic temperatures $\left({ }^{\circ} \mathrm{C}\right)$ of exposed testes in bulls and rams

\begin{tabular}{|c|c|c|c|c|c|c|}
\hline \multirow[b]{2}{*}{ Location } & \multicolumn{2}{|c|}{ Surface } & \multicolumn{2}{|c|}{ Subtunic } & \multicolumn{2}{|c|}{$\begin{array}{l}\text { Difference between } \\
\text { surface and subtunic } \\
\text { temperature }\end{array}$} \\
\hline & Bull & Ram & Bull & Ram & Bull & Ram \\
\hline Top & $27.8 \pm 0.6$ & $31.2 \pm 0.5^{\mathrm{d}}$ & $28.4 \pm 0.5^{a}$ & $29.9 \pm 0.6^{d}$ & $-0.6^{*}$ & $1.3^{*}$ \\
\hline Middle & $27.9 \pm 0.6$ & $30.0 \pm 0.5^{c}$ & $28.6 \pm 0.5^{a}$ & $30.0 \pm 0.6^{\mathrm{d}}$ & -0.7 & 0.0 \\
\hline Bottom & $27.8 \pm 0.6$ & $28.7 \pm 0.9^{\circ}$ & $29.1 \pm 0.5^{\mathrm{b}}$ & $30.2 \pm 0.6^{\mathrm{e}}$ & $-1.3^{* *}$ & $-1.5^{*}$ \\
\hline Gradient & 0.0 & 2.5 & -0.7 & -0.3 & $0.7 * * *$ & $2.8^{* * *}$ \\
\hline
\end{tabular}

Within columns, means with different superscripts are significantly different $\left({ }^{\text {abc }} P<0.01,{ }^{3 c} P<0.05\right)$.

Superscripts for temperature difference indicate significance $\left({ }^{*} P<0.10,{ }^{* *} P<0.05, * * * P<0.01\right)$.

were significant positive gradients for scrotal subcutaneous temperature in both the presence and absence of a testis (1.0 and $2.1^{\circ} \mathrm{C}$, respectively; Table 2). Scrotal surface and scrotal subcutaneous temperatures (at all three locations) and their gradients were not significantly different when a testis was present compared with when it was removed.

The intratesticular temperature gradient for the covered testis $\left(-0.2^{\circ} \mathrm{C}\right)$ was not significant (Table 3). However, intratesticular temperatures at all three locations were substantially lower $(P<0.001)$ when the testis was exposed, and the gradient $\left(-0.5^{\circ} \mathrm{C}\right)$ was significant $(P<0.01)$. The exposed testis had no surface temperature gradient but did have a significant negative subtunic temperature gradient $\left(-0.7^{\circ} \mathrm{C}\right.$; Table 4). There were differences between testicular surface and subtunic temperatures at the top and bottom of the testes $(P<0.1$ and $P<0.05$, respectively).

There was a significant positive intraepididymal temperature gradient for the covered testis $\left(2.4^{\circ} \mathrm{C}\right.$; Table 5$)$. When the testis 
Table 5. Mean ( \pm SEM) intraepididymal temperatures $\left({ }^{\circ} \mathrm{C}\right)$ when covered by the scrotum or exposed in bulls

\begin{tabular}{lccc}
\hline Location & Covered & Exposed & $\begin{array}{c}\text { Effect of scrotum } \\
\text { on intraepididymal } \\
\text { temperature }\end{array}$ \\
\hline Caput & $34.9 \pm 0.2^{\mathrm{a}}$ & $29.1 \pm 1.3^{\mathrm{ab}}$ & $5.9^{*}$ \\
Corpus & $33.5 \pm 0.2^{\mathrm{b}}$ & $29.8 \pm 0.7^{\mathrm{a}}$ & $3.8^{*}$ \\
Cauda & $32.6 \pm 0.4^{\mathrm{c}}$ & $28.0 \pm 0.6^{\mathrm{b}}$ & $4.6^{*}$ \\
Gradient & 2.4 & 1.1 & 1.3 \\
\hline
\end{tabular}

Within columns, means having different superscripts are significantly different $\left({ }^{\mathrm{abc}} P<0.05\right)$.

*Temperature difference is significant $(P<0.001)$.

was exposed, intraepididymal temperatures decreased significantly; the intraepididymal temperature gradient remained positive but was not significant.

In Expt 2 (rams), there were no differences $(P>0.05)$ between scrotal surface temperature measurements made before epidural analgesia and those made just before surgery. Scrotal surface temperatures before the epidural compared with those just before surgery were 32.9 and 32.9 (top), 31.7 and 32.3 (middle) and 26.9 and $28.1^{\circ} \mathrm{C}$ (bottom). All other measurements reported were obtained after surgery. Scrotal surface temperature gradients were significant and similar with or without a testis $\left(3.5\right.$ and $3.6^{\circ} \mathrm{C}$, respectively; Table 1 ). Similarly, scrotal subcutaneous temperature gradients were positive and significant with or without a testis $\left(0.7\right.$ and $2.3^{\circ} \mathrm{C}$; Table 2). Testis removal affected top and bottom scrotal subcutaneous temperature and the scrotal subcutaneous temperature gradient $\left(-0.8,0.8\right.$ and $\left.-1.6^{\circ} \mathrm{C} ; P<0.01\right)$.

There were negative $(P<0.01)$ intratesticular temperature gradients for both covered and exposed testes $(-0.6$ and $-0.5^{\circ} \mathrm{C}$; Table 3), with profoundly lower $(P<0.0001)$ intratesticular temperatures at all three locations for exposed testes. There were significant gradients for both surface and subtunic temperatures for exposed testes $\left(2.5\right.$ and $-0.3^{\circ} \mathrm{C}$; Table 4$)$. Surface temperature of exposed testes tended $(P<0.10)$ to be higher than subtunic temperature at the top of the testis but lower at the bottom (difference, 1.3 and $-1.5^{\circ} \mathrm{C}$ ).

\section{Discussion}

When a testis was removed from the scrotum, the scrotum had a positive temperature gradient and the testis had a negative temperature gradient. Therefore, both hypotheses were supported. These opposing temperature gradients may be related to vasculature. The scrotum is apparently vascularized from the top to the bottom. In contrast, the testicular artery exits the testicular vascular cone (just dorsal to the testis), courses the length of the testis to the ventral pole and then diverges into several smaller arteries that spread dorsally and laterally across the surface of the testis before entering the testicular parenchyma (Setchell, 1970).

Scrotal surface temperatures (including the positive temperature gradient) were similar to those previously reported in bulls (Riemerschmid and Quinlan, 1941; Coulter, 1988; Kastelic et al.,
1995) and rams (Fowler, 1968). In both bulls and rams, scrotal surface temperatures were not significantly different when a testis was present or absent. Therefore, scrotal surface temperature appears to be regulated primarily by the scrotum. Rams appeared to have a larger scrotal surface temperature gradient than did bulls $\left(3.5\right.$ versus $2.1^{\circ} \mathrm{C}$ ). This difference may be attributable to the higher body temperature in rams than in bulls $\left(39.5\right.$ versus $\left.38.5^{\circ} \mathrm{C}\right)$. However, intratesticular temperatures were similar. Perhaps the scrotal skin is thinner in rams, allowing more heat to be radiated from the testes to the scrotal surface.

Subcutaneous temperatures were similar to those previously reported in bulls (Kastelic et al., 1995) and in rams (Waites and Moule, 1961; Fowler, 1968). The effects of testis location (inside or outside the scrotum) on scrotal subcutaneous temperature and subcutaneous temperature gradient were consistent with complementary temperature gradients in the scrotum and testes. In bulls and rams when the testes were exposed, top and bottom subcutaneous temperature increased and the subcutaneous temperature gradient increased (differences significant only in rams).

Intratesticular temperatures were similar to those previously reported in bulls (Riemershmid and Quinlan, 1941; Coulter, 1988; Kastelic et al., 1995) and rams (Waites and Moule, 1961; Fowler, 1968). The negative temperature gradients in exposed testes were evident both under the tunica albuginea (subtunic temperature) and within the testes (intratesticular temperature). Surface temperatures of the exposed testes were not consistent with the negative gradients detected under the tunica albuginea or within the parenchyma, perhaps due to heat loss to the environment from a tissue that is not normally exposed. In bulls, there was no temperature gradient on the testicular surface, while in rams there was a significant, positive gradient. In rams only, small amounts of blood leaked from thermocouple insertion sites and ran ventrally. Although the testicular surface was blotted dry just before thermography, this wetter surface could have resulted in cooler temperatures and thus a positive gradient. Intratesticular temperature was substantially cooler at all locations for the exposed testis compared with the testis covered by the scrotum in both bulls and rams. However, decreases in intratesticular temperatures were very uniform (range $2.5-2.8^{\circ} \mathrm{C}$ ) and therefore there was no significant difference in these temperature gradients. Clearly the scrotum has a profound influence on intratesticular temperature.

Temperatures within the epididymides were similar to those reported by Kastelic et al. (1995). Temperatures in the caput, corpus and cauda epididymides were all substantially lower in exposed testes compared with covered testes, with the most profound decrease in the caput. Consequently, the intraepididymal temperature gradient for exposed testes was positive, but not significant. The low cauda intraepididymal temperature (cooler than intratesticular temperature) may be important for preservation of spermatozoa prior to ejaculation (Brooks, 1973). Vogler et al. (1991) reported an increased incidence of morphological defects occurring in the epididymides after scrotal insulation, emphasizing that the testes and epididymides must be maintained cooler than body temperature.

In conclusion, the scrotum and testes have opposing temperature gradients which apparently complement one another, 
resulting in a relatively uniform intratesticular temperature (below body core temperature). Furthermore, the scrotum substantially increased intratesticular temperature, but scrotal surface temperature was not significantly affected by the presence of a testis.

LRC Contribution No. 38795104 . Financial support was provided by the Alberta Agricultural Research Institute (Farming for the Future Project 920164), the Canada/Alberta Livestock Research Trust Inc., and Agriculture and Agri-Food Canada. Appreciation is expressed to T. Entz, F. Braat, R. McMahon, G. Wallins, and R. Wilde for technical assistance. Portions of these data were reported at the National Association of Animal Breeders 15th Technical Conference on Artificial Insemination and Reproduction in Milwaukee, WI, April, 1994.

\section{References}

Blazquez NB, Mallard GF and Wedd SR (1988) Sweat glands of the scrotum of the bull Journal of Reproduction and Fertility 83 673-677

Brooks DE (1973) Epididymal and testicular temperature in the unrestrained conscious rat Journal of Reproduction and Fertility 35 157-160

Carrick FN and Setchell BP (1977) The evolution of the scrotum. In Reproduction and Evolution pp 165-170 Eds JH Calaby and CH Tyndale. Biscoe Australian Academy of Science

Cook RB, Coulter GH and Kastelic JP (1994) The testicular vascular cone, scrotal thermoregulation, and their relationship to sperm production and seminal quality in beef bulls Theriogenology 41 653-671

Coulter GH (1988) Thermography of bull testes Proceedings of the 12th Technical Conference on Artificial Insemination and Reproduction, National Association of Animal Breeders Columbia pp 58-63
Coulter GH and Kastelic JP (1994) Testicular thermoregulation in bulls Proceedings of the 15th Technical Conference on Artificial Insemination and Reproduction National Association of Animal Breeders Columbia pp 28-34

Fowler DG (1968) Skin folds and Merino breeding 5. Variations in scrotal, testis and rectal temperatures as affected by site of measurement, acclimatization to heat and degree of skin fold Australian Journal of Experimental Agriculture and Animal Husbandry 8 125-132

Gunn SA and Gould TC (1975) Vasculature of the testes and adnexa. In Handbook of Physiology. Section 7 Endocrinology Vol 5, pp 117-142 Eds RO Greep and EB Astwood. American Physiological Society, Washington DC

Johnson RA and Wichern DW (1982) Applied Multivariate Statistical Analysis pp 226-289 Prentice-Hall Inc., Englewood Cliffs

Kastelic IP, Coulter GH and Cook RB (1995) Scrotal surface, subcutaneous, intratesticular, and intraepididymal temperatures in bulls Theriogenology $\mathbf{4 4}$ $147-152$

Riemerschmid G and Quinlan J (1941) Further observations on the scrotal skin temperature of the bull, with some remarks on the intra-testicular temperature Onderstepoort journal of Veterinary Science and Animal Industry 17 123-140

SAS Institute Incorporated (1989) SASISTAT User's Guide Version 6 Vol 1 SAS Institute Inc., Cary

Setchell BP (1970) Testicular blood supply, lymphatic drainage, and secretion of fluid. In The Testis pp 101-239 Eds AD Johnson, WR Gomes and NL Vandemark. Academic Press, New York

Setchell BP (1978) The scrotum and thermoregulation. In The Mammalian Testis pp 90-108 Ed. BP Setchell. Cornell University Press, Ithaca

Vogler CJ, Saacke RG, Bame JH, Dejarnette JM and McGilliard ML (1991) Effects of scrotal insulation on viability characteristics of cryopreserved bovine semen Journal of Dairy Science 74 3827-3835

Waites GMH (1970) Temperature regulation and the testis. In The Testis pp 241-279 Eds AD Johnson, WR Gomes and NL Vandemark. Academic Press, New York

Waites GMH and Moule GR (1961) Relation of vascular heat exchange to temperature regulation in the testis of the ram Journal of Reproduction and Fertility 2 213-224 